\title{
What science for Europe's 1992?
}

\section{An acid test of the European Community's intentions in support of science after 1992 is its willingness to respond to an imaginative proposal from radioastronomers.}

EVERYBODY in Europe is being conditioned by the European Commission to believe that 1992 will mark the arrival of the authentic common market in which goods and services will be traded freely, in which capital and people will flow with hardly any artificial interference to the places at which they will be most productive and in which prosperity will grow by leaps and bounds. It is a brave prospect, if somewhat tarnished by the knowledge that this is what should have happened more than 30 years ago, when the European Community was first formed, and by the suspicion that member governments will not instantly forget the stratagems they have learned for replacing tariff barriers by less tangible restraints of trade. Meanwhile, very little has been done to pose intelligently, let alone to answer, the question of what 1992 will do for science and technology. Will 1992 come and go without the question being raised?

With a budget exceeding $\$ 1,000$ million a year, the European Commission (the Community's executive branch) is already a big player in science and technology, but most of its present activities in the field will be inappropriate in the circumstances it hopes to have created by 1992. Most of the Commission's energy and money goes into industrially oriented projects such as ESPRIT, the information technology enterprise, in which grants for research and development are made to consortia of research and development groups, mostly industrial but with some academic participation. The goals of these projects are supposed to fall short of the development of products that can be sold, but success is meant to put their participants within reach of profitable markets. As things are, research and development projects qualify for the Commission's support only if the groups they involve are drawn from more than one member state. The rationale for this requirement is that of assisting technical change in a manner that spreads the benefits through more than one member state. The same condition must be satisfied by those in basic research who seek support from the Commission, which is spending upwards of $\$ 150$ million a year on projects spanning intra-Community frontiers. This pattern of spending, logical enough in present circumstances, will make no sense if 1992 does indeed accomplish what the Commission hopes.

\section{Reasons}

The reasons are straightforward. If 1992 means anything at all, it means that Europe is reconciled to the most efficient division of labour between European manufacturers (of software and hardware alike). Gone will be the time when it could be a legitimate policy objective of either member governments or the commission to ensure that, say, the electronics industry continues to flourish in this country or that. Ideally, this would imply that the Commission should be given powers to ensure that its member governments do not, by subterfuge, use national funds to subsidize the technical development of their own manufacturers. (The use of defence research and development contracts for this purpose is the most serious loophole, which should be closed.)

But, by the same test, the Commission itself should abandon its present pattern of support for industrial consortia spanning Europe's internal frontiers. If the intention is that industrial companies should compete freely with each other, it will make no sense that the Commission should be spending considerable sums of money to help weaker companies compete with the more successful.

That will bring comfort to some member governments, the British for example, which have been sceptical of the Commission's plans even in present circumstances. But none of that implies that the Commission can or should pull out of research support altogether. While 1992 will rob the Commission's programmes of applied research of their justification, the case for supporting basic research will be even stronger than it is now. Then, in heady 1992, the Commission will inevitably be the source of support in the last resort for the infrastructure of European science. Its function then should be to seek out and to support projects promising to add to Europe's strength in basic science which, for one reason or another, are not supported by national governments. With 1992 almost upon us, the Commission should be starting now to work in that direction.

\section{Disappointment}

That is why the commission's failure to support European radioastronomers' plans for strengthening their VLBI network are a cruel disappointment (see Nature 337, 301; 26 January 1989). By general consent, the project is an excellent way of making progress in an important field of basic science, but one which also has a potentially important industrial spin-off. The need is for a European centre at which signals recorded by several European radiotelescopes being used in concert as an interferometer can be electronically compared. Technically, the task is complicated because the amount of data gathered by each telescope can be huge and because, in Europe, there may be more than half a dozen independent signals to be compared. The spin-off is the opportunity to develop electronic machinery that is more suitable for this and other information-processing tasks than that now available (from the United States) and also cheaper. Yet the Commission has turned down the proposal on the grounds that none of its existing schemes for research support can accommodate the radioastronomers' ambitions. The amount of money required to launch the project would be too large a proportion of the budget of the committee called CODEST, which is the chief source of funds for basic research, while there would also be running costs which the Commission has no means of providing.

That puts the bureaucratic cart before the horse. If the Commission has no present scheme for supporting a project whose virtues are widely acknowledged, and which could play an important part in strengthening both European science and the ideal of European collaboration, there is a simple answer: the Commission should devise one. And it should do that quickly, however much it may fear that the VLBI consortium's plans, which entail the establishment of a permanent institution, will set an awkward precedent. For the truth is that institutionbuilding of that kind is crucial to the kind of function that will fall on the Commission's shoulders after 1992. The sooner the Com mission faces up to that prospect, the sooner it will persuade people that 1992 is really on the way. 